\title{
Brucella melitensis B115-based ELISA to unravel false positive serologic reactions in bovine brucellosis: a field study
}

\author{
Adriana Trotta ${ }^{*^{*}}$ D, Mariarosaria Marinaro ${ }^{2 \dagger}$, Margie Cirilli ${ }^{1}$, Alessio Sposato ${ }^{1}$, Rosanna Adone $^{2}$, Matteo Beverelli ${ }^{3}$, \\ Domenico Buonavoglia ${ }^{1}$ and Marialaura Corrente ${ }^{1}$
}

\begin{abstract}
Background: Brucellosis is a zoonosis whose incidence is not declining worldwide despite the global effort to control the disease. Accurate and precise diagnosis is a crucial step in any prophylaxis program but single tests to unequivocally detect animals infected with Brucella spp. are currently unavailable. In Italy, serological diagnosis of bovine brucellosis is performed with two official tests: a rapid agglutination test (i.e., Rose Bengal Plate test, RBPT) and a complement fixation test (CFT) that detect antibodies directed mainly to the smooth lipopolysaccharide (SLPS). Neither of the two tests is able to avoid the detection of false positive serological reactions (FPSRs) caused by bacteria sharing S-LPS components with Brucella spp. and responsible for the single reactors (SR) phenomenon. A B. melitensis R strain-based ELISA showed a good diagnostic performance in unravelling FP animals; however, since a limited number of animals were analyzed in that study, a large field study was conducted here to discriminate between Brucella-infected from FP animals, with the final aim of reducing the unnecessary slaughter of the latter. An ELISA based on a R strain of Brucella, i.e., Brucella melitensis B115, was employed to measure specific lgG responses in a collection of bovine sera $(n=648)$. Sera were obtained from 180 farms (either officially brucellosisfree or not brucellosis-free) recruited during an extended period of time (2014-2018) and were preliminarily assayed with the official tests by the Italian Reference Centers and then subjected to the ELISA.

Results: Negative sera, when subjected to the ELISA, gave O.D. values below the cutoff; SR sera, i.e. RBPT positive and CFT negative, as well as double positive (DP) sera, i.e. RBPT and CFT positive, gave O.D. values that were below the cutoff. All positive sera, i.e. from Brucella-infected animals, were RBPT positive and CFT positive (ICFTU ranging from 20 to 1280) and gave ELISA O.D. values above the cutoff.

Conclusions: The B. melitensis B115-based ELISA systematically unravelled all false positive (FP) sera while confirming the diagnosis in Brucella-infected animals. Thus, the test employed in the present study may complement the official assays to avoid the costly slaughter of FP animals.
\end{abstract}

Keywords: Brucellosis diagnosis, Serology, ELISA test

\section{Background}

Brucellosis is an ancient and re-emerging zoonosis occurring worldwide [1]; it is caused by bacteria belonging to the genus Brucella which infect a variety of mammals and cause abortion and infertility in domestic animals [2]. Some Brucella species, such as B. abortus and B.

\footnotetext{
*Correspondence: adriana.trotta@uniba.it

${ }^{+}$Adriana Trotta and Mariarosaria Marinaro contributed equally to this work. 'Department of Veterinary Medicine, University of Bari "Aldo Moro", Str. Prov. per Casamassima Km 3, 70010 Valenzano, BA, Italy

Full list of author information is available at the end of the article
}

melitensis, are mainly transmitted to humans by the consumption of contaminated dairy products and may cause a severe debilitating disease. Reduction of the global burden of human infection could be reached only by controlling animal disease [3, 4]. Control measures for animal brucellosis are different in different geographic areas and range from vaccination to test-and-slaughter programs although both approaches complement to reliable diagnosis [1]. Bacterial isolation and identification is clearly the gold standard diagnostic method but it is

(c) The Author(s). 2020 Open Access This article is distributed under the terms of the Creative Commons Attribution 4.0 International License (http://creativecommons.org/licenses/by/4.0/), which permits unrestricted use, distribution, and 
time consuming and impractical since it is performed on organs from slaughtered animals; in addition, the low isolation rate from infected tissues often results in false negatives $[1,5]$. Serologic assays are rapid and simple systems to detect infected animals; several tests based on different principles have been developed worldwide to reach a good level of specificity and sensitivity although neither ideal nor unique serological test is available to precisely diagnose animal brucellosis [6-8]. Mediterranean countries are not brucellosis-free; in particular, in Italy the disease occurs in ruminants with low prevalence in Southern regions and, since vaccination is not allowed, the test-and-slaughter strategy together with sero-epidemiological surveillance programs are in force to control the disease in these areas. Diagnosis of bovine brucellosis is based on two official serological tests: a rapid agglutination test (i.e., Rose Bengal Plate test, RBPT) and a complement fixation test (CFT) [9]. Both tests are routinely performed by the Italian Reference Centers (Istituti Zooprofilattici, IZS) and use whole bacteria as antigen, i.e., Brucella abortus (S 99 strain), to detect antibodies directed against the immunodominant O-chain of smooth lipopolysaccharide (S-LPS) of Brucella [10]. The sequential use of both tests allows the detection of infected animals but false positive serological reactions (FPSRs) are also detected since other Gram-negative bacteria (e.g., Salmonella spp., Escherichia coli $\mathrm{O} 157$ or Yersinia enterocolitica O:9) share SLPS components with Brucella spp. Indeed, Y. enterocolitica $0: 9$ infections are frequent in bovine herds [11, 12] and generate FPSRs indistinguishable, by the official tests, from true positives [13]. The existence of FPSRs is a huge economical issue especially for brucellosis-free farms since brucellosis is a reportable disease and, according to the local Regulations operating in Apulia and Basilicata, the suspected presence of infected animals (RBPT positive/CFT positive or RBPT negative/ CFT positive), but also the detection of potential FP animals, determines the loss of the brucellosis-free status and the slaughter of the seropositive animals. Crossreactions have been reported not only in ruminants but also in pigs and humans because no individual specific test is available in any species $[6,11,12,14]$. Thus, there is an urgent need for highly specific serological assays to implement brucellosis diagnosis and several tests based on other Brucella antigens have indeed been developed [15-17]. Rough (R) Brucella strains (such as B.abortus RB51, B.melitensis B115, B.ovis and B.canis), lacking the O-PS chain in the outer membrane of the cell wall, do not elicit cross-reactive antibodies against S-LPS and can be used to design more specific assays [18-21]. In particular, B. melitensis B115 was recently used as antigen to develop an ELISA [22] with good diagnostic performances but the paucity of bovine samples screened in that study prompted us to test it in a systematic field study. Thus, to specifically address this need, a large field study was conducted in a geographic area with low disease prevalence to unravel FP animals, with the final aim of reducing their unnecessary slaughter.

\section{Results}

Serum samples were collected during the period 20142018, from 180 farms either officially brucellosis-free (163 farms) or not brucellosis-free (17 farms) and all located in two regions of South Italy, i.e., Apulia and Basilicata. Sera were first subjected by the IZS to the official assays, i.e. RBPT and CFT, were subdivided into four groups (A, B, C, D) and were then assayed by the ELISA (Tables 1 and 2). Negative sera $(n=259$; group A, Table 1) were from officially brucellosis-free farms, they tested both RBPT and CFT negative and when subjected to the ELISA they all gave an O.D. value below the cutoff value (O.D. 0.143) which was previously determined by a ROC analysis [22] and was not significantly different from that calculated in the present study (O.D. $0.141 ; p>0.05)$. A considerable number of SR, i.e. RBPT positive and CFT negative $(n=150$; group B; Table 1$)$, and of DP sera, i.e. RBPT and CFT positive $(n=134$; group C; Table 1) were also tested and both groups gave O.D. values that were below the cutoff and not significantly different from those of group A ( $p>0.05$; Table $1)$. The CFT titers, expressed as International Complement Fixation Test Units (ICFTU), ranged from 20 to 80 in DP sera $(n=134$; group C; Table 1$)$. Indeed, postmortem bacteriological and PCR analyses confirmed the absence of Brucella spp. in all samples tested (group B and C) while $Y$. enterocolitica O:9 was detected in 130 fecal samples from SR $(n=150$; group $B$; Table 1$)$ and in 100 DP animals $(\mathrm{n}=134$; group C; Table 1 ) (data not shown). Finally, Table 2 shows the comparison of all serological data obtained from Brucella-infected animals. All Group D sera $(n=105)$ tested RBPT positive and CFT positive (ICFTU ranging from 20 to 1280) and gave ELISA O.D. values above the cutoff. The individual ELISA O.D. values reported in Table 2 did not correlate with the relative ICFTU when subjected to linear regression analysis (data not shown).

Finally, also the measurement of the percentile (99\%) of the O.D. values obtained from brucellosis-free animals $(n=259$; group A, Table 1$)$ enabled to fully discriminate between uninfected and Brucella-infected animals (data not shown) [23].

The OIE international standard serum was included as positive control in the ELISA tests; it was tested in 10 replicates and gave always positive readings (O.D. $0.481 \pm 0.005$ ). 
Table 1 Comparison of the B.melitensis B115-based ELISA with Rose Bengal Plate Test (RBPT) and Complement Fixation Test (CFT) in brucellosis-free herds

\begin{tabular}{|c|c|c|c|c|}
\hline \multirow[t]{2}{*}{ ANIMALS } & \multirow[t]{2}{*}{ NUMBER } & \multicolumn{3}{|c|}{ SEROLOGICAL TEST } \\
\hline & & RBPT & CFT & ELISA (O.D. \pm SD) \\
\hline Group A. Negativeł & 259 & Negative & Negative & $0,063 \pm 0,026$ \\
\hline Group B. Single Reactors^ & 150 & Positive & Negative & $0,087 \pm 0,013$ \\
\hline Group C. Double Positive & 134 & Positive & Positive $^{\circ}$ & $0,086 \pm 0,011$ \\
\hline
\end{tabular}

\# animals tested negative to both official tests

$\wedge$ animals tested positive only to one official test

$\S$ animals tested positive to both official tests

- International Complement Fixation Test Units (ICFTU) ranged from 20 to 80

\section{Discussion}

Despite the efforts made worldwide to control and eventually eradicate brucellosis, the disease remains one of the most common bacterial zoonoses with a constantly changing geographical distribution. Reducing the global burden of animal brucellosis will decrease the incidence of the disease in humans and compliance to control programs together with accurate diagnosis are instrumental to achieve this goal. The use of different strategies to control the disease, as well as the lack of diagnostic tests able to unequivocally diagnose the infection, impairs the effectiveness of control programs [1, 8]. In addition, the presence of FPSRs imposes the use of combined seroepidemiologic methods and the development of better tests to implement diagnosis in animals. This is particularly urgent in areas with low disease prevalence such as the Mediterranean countries. Results reported here show that a B. melitensis B115-based ELISA is able not only to confirm the diagnosis made with the official tests but, most importantly, it can help unveil ambiguous FPSRs. According to the Italian prophylaxis Regulations, an animal is considered infected with Brucella spp. when testes both RPBT positive and CFT positive. However, in Southern Regions of Italy, that are not brucellosis-free, the local Regulations impose to evaluate both the anamnesis and the epidemiological data of farmed animals (especially those from officially brucellosis-free farms) that result SR or DP after completing the official serological tests. In fact, according to the local Regulations, if an animal testes RPBT positive and CFT negative (the so-called SR) both tests are repeated two weeks later [24] meanwhile the herd loses the official brucellosisfree status. Whether the second analysis confirms the first result (RPBT positive and CFT negative) or gives positive results for both tests, the animal is slaughtered even if the epidemiological evidences exclude the presence of Brucella infections in that herd. Cross-reactivity with other Gram-negative bacteria sharing the S-LPS antigens may explain the detection of SR or DP animals in those officially brucellosis-free herds that unexpectedly show seropositive animals during serological controls [25]. To complicate the issue, the herd whose brucellosis-free status has been lost, can reacquire it when all seropositive animals have been slaughtered and when none of the remaining animals tests positive to three consecutive serological tests: two made at a 3weeks interval and a final one made 3-6 months later. Thus, the brucellosis-free status can be re-established not earlier than 5-7 months after notification (even in the presence of only one SR or one DP animal). For the considerable economic losses due to the slaughter of SR/ DP animals and the lengthy suspension of the brucellosis-free status, the development of more specific serological tests, to precisely diagnose brucellosis, is highly desirable. Ancillary serologic tests to be performed alongside the official tests may serve the cause and the use of Brucella antigens other than the whole bacteria or S-LPS, has been exploited in the past [15, 16]. The B. melitensis $\mathrm{R}$ strain employed here proved to be a good antigen to unravel FP animals in a large field study conducted in a geographic area with low disease prevalence (prevalence of bovine brucellosis $2.06 \%$ in Apulia and $0.67 \%$ in Basilicata) [24].

The official serological assays performed by the IZS provide a dual level of information on specific antibody responses to Brucella: RBPT, which is used as a screening qualitative test, detects agglutinating antibodies while CFT provides a quantitative measure of complement fixing antibodies. In fact, sera with ICFTU equal to or above 20 are considered positive. In the present study the O.D. values measured with the ELISA did not correlate with the ICFTU, a finding consistent with previous observations $[22,26]$ and that is likely due to the different nature of the two tests. Indeed, the ELISA reported here likely measures the total amount of IgG directed against a plethora of Brucella antigens, within the bacterial extract. While this can be viewed as a limitation of the study, it suggests instead that this ELISA could be exploited in the future to dissect the whole humoral responses in infected animals by determining for instance: i) the level of antibody isotypes / subclasses specific to Brucella and ii) the antigens, other than the immunodominant S-LPS, against which those antibodies are produced during infection and disease. 
Table 2 Comparison of the B. melitensis B115-based ELISA with Rose Bengal Plate Test (RBPT) and Complement Fixation Test (CFT) in animals infected with Brucella

\begin{tabular}{|c|c|c|c|}
\hline Group $D \wedge$ animal number & RBPT & ICFTU & ELISA O.D. \\
\hline 1 & positive & 20 & 0.300 \\
\hline 2 & positive & 20 & 0.460 \\
\hline 3 & positive & 20 & 0.279 \\
\hline 4 & positive & 20 & 0.272 \\
\hline 5 & positive & 20 & 0.268 \\
\hline 6 & positive & 20 & 0.254 \\
\hline 7 & positive & 20 & 0.268 \\
\hline 8 & positive & 20 & 0.170 \\
\hline 9 & positive & 20 & 0.175 \\
\hline 10 & positive & 20 & 0.246 \\
\hline 11 & positive & 20 & 0.246 \\
\hline 12 & positive & 20 & 0.165 \\
\hline 13 & positive & 40 & 0.288 \\
\hline 14 & positive & 40 & 0.376 \\
\hline 15 & positive & 40 & 0.220 \\
\hline 16 & positive & 40 & 0.274 \\
\hline 17 & positive & 40 & 0.318 \\
\hline 18 & positive & 40 & 0.212 \\
\hline 19 & positive & 40 & 0.154 \\
\hline 20 & positive & 40 & 0.280 \\
\hline 21 & positive & 40 & 0.240 \\
\hline 22 & positive & 40 & 0.151 \\
\hline 23 & positive & 40 & 0.244 \\
\hline 24 & positive & 40 & 0.260 \\
\hline 25 & positive & 40 & 0.385 \\
\hline 26 & positive & 40 & 0.367 \\
\hline 27 & positive & 40 & 0.302 \\
\hline 28 & positive & 40 & 0.256 \\
\hline 29 & positive & 40 & 0.280 \\
\hline 30 & positive & 40 & 0.240 \\
\hline 31 & positive & 40 & 0.300 \\
\hline 32 & positive & 40 & 0.260 \\
\hline 33 & positive & 80 & 0.280 \\
\hline 34 & positive & 80 & 0.362 \\
\hline 35 & positive & 80 & 0.300 \\
\hline 36 & positive & 80 & 0.310 \\
\hline 37 & positive & 80 & 0.206 \\
\hline 38 & positive & 80 & 0.394 \\
\hline 39 & positive & 80 & 0.226 \\
\hline 40 & positive & 80 & 0.283 \\
\hline 41 & positive & 80 & 0.310 \\
\hline 42 & positive & 80 & 0.388 \\
\hline
\end{tabular}

Table 2 Comparison of the B. melitensis B115-based ELISA with Rose Bengal Plate Test (RBPT) and Complement Fixation Test (CFT) in animals infected with Brucella (Continued)

\begin{tabular}{|c|c|c|c|}
\hline aroup $\mathrm{D}^{\wedge}$ animal number & RBPT & ICFTU $^{\circ}$ & ELISA O.D \\
\hline 3 & positive & 80 & 0.396 \\
\hline 4 & positive & 80 & 0.288 \\
\hline & positive & 80 & 0.304 \\
\hline & positive & 80 & 0.336 \\
\hline & positive & 80 & 0.340 \\
\hline & positive & 80 & 0.144 \\
\hline & positive & 80 & 0.144 \\
\hline & positive & 80 & 0.146 \\
\hline & positive & 80 & 0.161 \\
\hline & positive & 80 & 0.155 \\
\hline & positive & 80 & 0.153 \\
\hline & positive & 80 & 0.146 \\
\hline & positive & 160 & 0.370 \\
\hline & positive & 160 & 0.288 \\
\hline & positive & 160 & 0.296 \\
\hline & positive & 160 & 0.218 \\
\hline & positive & 160 & 0.146 \\
\hline & positive & 160 & 0.221 \\
\hline & positive & 160 & 0.240 \\
\hline & positive & 160 & 0.266 \\
\hline & positive & 160 & 0.260 \\
\hline & positive & 160 & 0.216 \\
\hline & positive & 160 & 0.392 \\
\hline & positive & 160 & 0.366 \\
\hline & positive & 160 & 0.210 \\
\hline & positive & 160 & 0.372 \\
\hline & positive & 160 & 0.396 \\
\hline Q & positive & 160 & 0.374 \\
\hline & positive & 160 & 0.292 \\
\hline & positive & 320 & 0.280 \\
\hline & positive & 320 & 0.294 \\
\hline & positive & 320 & 0.212 \\
\hline & positive & 320 & 0.280 \\
\hline & positive & 320 & 0.171 \\
\hline & positive & 320 & 0.237 \\
\hline & positive & 320 & 0.231 \\
\hline & positive & 320 & 0.299 \\
\hline & positive & 320 & 0.345 \\
\hline & positive & 320 & 0.320 \\
\hline & positive & 320 & 0.266 \\
\hline & positive & 320 & 0.392 \\
\hline & positive & 320 & 0.237 \\
\hline
\end{tabular}


Table 2 Comparison of the B. melitensis B115-based ELISA with Rose Bengal Plate Test (RBPT) and Complement Fixation Test (CFT) in animals infected with Brucella (Continued)

\begin{tabular}{|c|c|c|c|}
\hline Group $\mathrm{D}^{\wedge}$ animal number & RBPT & ICFTU $^{\circ}$ & ELISA O.D. \\
\hline 85 & positive & 320 & 0.374 \\
\hline 86 & positive & 320 & 0.378 \\
\hline 87 & positive & 320 & 0.244 \\
\hline 88 & positive & 640 & 0.234 \\
\hline 89 & positive & 640 & 0.232 \\
\hline 90 & positive & 640 & 0.234 \\
\hline 91 & positive & 640 & 0.389 \\
\hline 92 & positive & 640 & 0.400 \\
\hline 93 & positive & 640 & 0.385 \\
\hline 94 & positive & 640 & 0.284 \\
\hline 95 & positive & 640 & 0.378 \\
\hline 96 & positive & 640 & 0.314 \\
\hline 97 & positive & 640 & 0.300 \\
\hline 98 & positive & 640 & 0.200 \\
\hline 99 & positive & 1280 & 0.426 \\
\hline 100 & positive & 1280 & 0.420 \\
\hline 101 & positive & 1280 & 0.467 \\
\hline 102 & positive & 1280 & 0.368 \\
\hline 103 & positive & 1280 & 0.390 \\
\hline 104 & positive & 1280 & 0.390 \\
\hline 105 & positive & 1280 & 0.380 \\
\hline
\end{tabular}

Andividual serum samples, $\mathrm{n}=105$, both RBPT and CFT positive, collected from 17 different Brucella-infected herds; the infection with Brucella spp. was confirmed by bacteriological and PCR analyses

- International Complement Fixation Test Units (ICFTU)

\section{Conclusions}

Brucellosis is a serious disease with implications for both international trade and public health $[1,4]$ and its incidence is not declining despite the effort made worldwide. It is also paradigmatic of zoonoses requiring a multidisciplinary and coordinated One Health approach to achieve the goal of eradication. Since new reservoir hosts in wildlife and new Brucella species are being discovered, it is a global responsibility to control the disease, at any level, to reduce chances for Brucella spp. to infect new hosts and to conquer new animal/environment/human interfaces [4]. Specific diagnosis is a crucial first step to unequivocally detect infected animals for their subsequent management. Until single reliable diagnostic tests become available, multiple tests based on different principles should be applied especially to sera giving discordant results. The ELISA employed in the present study may complement official tests when aspecific serological reactions occur during brucellosis testing, in order to avoid the costly slaughter of FP animals infected with other Gram-negative bacteria.

\section{Methods}

Preparation of B. melitensis B115 extracts

B. melitensis attenuated strain B115 was provided by the Veterinary Laboratories Agency (VLA) of Weybridge (U.K.) and cultured to prepare the bacterial extract according to previously described protocols [21, 22].

Briefly, the bacteria were cultured in 11 of Brucella broth (Becton Dickinson, France) at $37^{\circ} \mathrm{C}$ in aerobic conditions under stirring for 3 days. When the culture reached an optical density (OD) of 2.080, the broth was centrifuged at $5000 \mathrm{~g}$ (ALC PK131R centrifuge, Milan, Italy) for $20 \mathrm{~min}$. The pellet was washed with saline solution, inactivated at $100^{\circ} \mathrm{C}$ for $10 \mathrm{~min}$, sonicated, centrifuged and the supernatant was dialysed against distilled water before measurement of the protein content as previously described by Corrente et al. 2015 .

\section{Herds and serum samples}

One hundred eighty herds from the South of Italy (Apulia and Basilicata regions) were recruited over an extended period of time, i.e. from 2014 to 2018. All animals were screened by the IZS during official brucellosis survey. A total of 648 sera were collected and subjected to the official diagnostic assays (RBPT and CFT) before testing them with the B. melitensis B115based ELISA. The sera were subdivided into 4 different groups.

Group A: serum samples, both RBPT and CFT negative $(n=259)$, that were collected from 11 officially brucellosis-free herds;

Group B: serum samples from SR animals $(n=150)$ tested positive in RBPT and negative in CFT; they were collected from 102 different officially brucellosisfree herds. These animals were slaughtered according to the local Regulations and the IZS tested for the absence of Brucella spp. infection by using both bacteriological testing (PT/DIA/004) and real-time PCRs $[9,27]$. In addition, fecal swabs were screened for Yersinia enterocolitica O:9 by official tests performed at the IZS (UNI EN ISO 10273:2017).

Group C: serum samples $(n=134)$, that tested positive in both serological conventional tests and were collected from 50 officially brucellosis-free herds; although epidemiological data indicated that they could be FP, these animals were slaughtered to fulfill the local Regulations. As for Group B, the absence of Brucella spp. infection was tested post-mortem and the screening for $Y$. enterocolitica O:9 was performed by IZS as previously described.

Group D: serum samples $(n=105)$ were both RBPT and CFT positive and were collected from 17 Brucellainfected herds. The animals were slaughtered and infection with Brucella spp. was confirmed by bacteriological 
and PCR analyses performed post-mortem by the IZS as described elsewhere $[9,27]$.

\section{Serological tests}

Serological conventional tests were performed by the IZS according to international standard procedures [9] while the ELISA was carried out in the Laboratory of Bacteriology at the University of Bari according to a previously described protocol with some modifications [22]. Briefly, polysorp microtiter plates (Nunc, Milan, Italy) were coated with $100 \mu \mathrm{l}$ of bacterial extract $(25 \mu \mathrm{g}$ of proteins/ $\mathrm{ml}$ ) in carbonated buffer and incubated overnight at $4{ }^{\circ} \mathrm{C}$ under gentle shaking. The plates were then washed four times with PBS containing $0.05 \%$ Tween 20 (PBS-T) and wells were blocked for $150 \mathrm{~min}$ at $37^{\circ} \mathrm{C}$ with $0.2 \%$ gelatin in carbonate buffer. After repeated washes, $100 \mu \mathrm{l}$ of serum, diluted 1:100 in PBS-T, were added and the plates were incubated at $37^{\circ} \mathrm{C}$ for 120 min. After washings, a rabbit anti-bovine antibody labeled with peroxidase (Sigma Aldrich, Milan, Italy) was diluted 1:3000 in PBS-T and added to the plates which were then incubated for $60 \mathrm{~min}$ at $37^{\circ} \mathrm{C}$. After final washings, an ABTS [2.2'-Azino-di-(3-ethylbenzothiazoline sulfonate)] solution (Sigma Aldrich, Milan, Italy) was added to each well and the plate was incubated at room temperature, without light for $20 \mathrm{~min}$. The O.D. was measured at $405 \mathrm{~nm}$ using an automated ELISA reader. The negative samples (group A, $n=259$ ) were used to determine the cut-off value of the ELISA test (i.e., the arithmetic mean of the O.D. of all negative samples plus 3 standard deviations).

The OIE international standard serum, supplied by the OIE Reference Laboratory for brucellosis at the VLA (Weybridge, UK), was used as positive control serum.

\section{Data analysis}

The Microsoft Excel 2010 program was employed to evaluate: i) the arithmetic mean and the standard deviation of O.D. values within a single group of animals; ii) the comparison of O.D. values between different animal groups (by chi square test with Yates correction); iii) the linear regression analysis between ICFTU and O.D. values in Brucella-infected animals (Group D); the percentile $(99 \%)$ of O.D. values obtained in uninfected animals (Group A).

A $p$ value below 0.05 was considered significant.

\section{Abbreviations}

CFT: Complement Fixation Test; DP: Double positive; FP: False positive; FPSR: False positive serological reaction; ICFTU: International Complement Fixation Test Units; IZS: Italian Reference Centers (Istituti Zooprofilattici); O.D.: Optical density; RBPT: Rose Bengal Plate test (rapid agglutination test); S-LPS: O-chain of smooth lipopolysaccharide; SR: Single reactors

Acknowledgements

Not applicable.

\section{Authors' contributions}

Design of the work: MM, MC2, RA; Data acquisition: MB, AT, AS; Analysis: AT, MC1; Interpretation of data: DB, MM, AT; Draft the work: AT, MM, MC2. All Authors have approved the re-submitted version (and any substantially modified version that involves the authors' contribution to the study). All authors have agreed both to be personally accountable for the authors' own contributions and to ensure that questions related to the accuracy or integrity of any part of the work, even ones in which the author was not personally involved, are appropriately investigated, resolved, and the resolution documented in the literature.

\section{Funding}

The work was funded by the Italian Ministry of Health, Project n. IZS PB 09/ 15; Matteo Beverelli, Marialaura Corrente, Mariarosaria Marinaro were Principal Investigators of the Unit 1, 2 and 3, respectively. The Ministry of Health had no role in designing the study, collecting and analysing the samples, interpreting the data, writing the manuscript.

\section{Availability of data and materials}

The datasets used and/or analyzed during the current study are available from the corresponding author on reasonable request.

\section{Ethics approval and consent to participate}

The results of the field study reported in the manuscript were obtained by analyzing bovine sera that had been already screened by the IZS. According to the national Regulations O.M. 28/5/2015 and O.M. 11/5/2018, the IZS PB (Istituto Zooprofilattico di Puglia e Basilicata) is the Center responsible for collecting sera (from all farms located in Apulia and Basilicata) in order to perform the two official assays within the national brucellosis control plans. According to the above Regulations, the ethics approval was waived and the consent to participate and the permission to collect specimens are (not only) unnecessary but the owners must provide to the IZS all the samples required for the subsequent official, mandatory, screening. Once the sera have been collected and screened by the IZS PB, they are available for any additional research aimed at improving the specificity of brucellosis diagnosis (provided that the studies are conducted in collaboration with the IZS PB and are funded by the Ministry of Health). Indeed, the present study was funded by the Ministry of Health, was performed in collaboration with the IZS PB, all sera were employed to test a potential, new, ancillary diagnostic assay and, therefore, met all requirements predicted by the national laws and regulations.

\section{Consent for publication}

Not applicable.

\section{Competing interests}

The authors declare that they have no competing interests.

\section{Author details}

'Department of Veterinary Medicine, University of Bari "Aldo Moro", Str. Prov. per Casamassima Km 3, 70010 Valenzano, BA, Italy. ${ }^{2}$ Department of Infectious Diseases, Istituto Superiore di Sanità, Viale Regina Elena 299, 00161 Rome, Italy. ${ }^{3}$ Istituto Zooprofilattico Sperimentale di Puglia e Basilicata (IZSPB), Sezione di Putignano, Contrada San Pietro Piturno, 70017 Putignano, BA, Italy.

Received: 20 June 2019 Accepted: 6 February 2020

Published online: 11 February 2020

\section{References}

1. Seleem MN, Boyle SN, Sriranganathan N. Brucellosis: a re-emerging zoonosis. Vet Microbiol. 2010;140:392-8.

2. Golding B, Scott DE, Scharf OL, Huang Y, Zaitseva M, Lapham C, Eller N, Golding H. Immunity and protection against Brucella abortus. Microbes Infect. 2001;3:43-8.

3. Verger JM, Grimont F, Grimont PA, Grayon M. Taxonomy of the genus Brucella. Ann Inst Pasteur Microbiol. 1987;138:235-8.

4. Godfroid J, Scholz HC, Barbier T, Nicolas C, Wattiau P, Fretin D, Whatmore AM, Cloeckaert A, Blasco JM, Moriyon I, Saegerman C, Muma JB, Al Dahouk S, Neubauer H, Letesson JJ. Brucellosis at the animal/ 
ecosystem/human interface at the beginning of the $21^{\text {st }}$ century. Prev. Vet. Med. 2011;102:118-31.

5. Corbel MJ. Identification of the immunoglobulin class active in the Rose Bengal plate test for bovine brucellosis. J. Hyg (Lond). 1972;70(4):779-95.

6. Nielsen K. Diagnosis of brucellosis by serology. Vet Microbiol. 2002;90:447-59.

7. Ducrotoy MJ, Conde-Alvarez R, Blasco JM, Moriyon I. A review of the basis of the immunological diagnosis of ruminant brucellosis. Vet Immunol Immunopathol. 2016;171:81-102.

8. Ducrotoy MJ, Munoz PM, Conde-Älvarez R, Blasco JM, Moriyon I. A systematic review of current immunological tests for the diagnosis of cattle brucellosis. Prev Vet Med. 2018;151:57-72.

9. OIE. Manual of Diagnostic Tests and Vaccines for Terrestrial Animals 2019. http://www.oie.int/standard-setting/terrestrial-manual/access-online/. Accessed 1 Jan 2019

10. Bricker BJ. Diagnostic strategies used for the identification of Brucella. Vet Microbiol. 2002;90:433-4.

11. Weynants V, Tibor A, Denoel PA, Saegerman C, Godfroid J, Thiange P, Letesson JJ. Infection of cattle with Yersinia enterocolitica O:9 a cause of the false serological reactions in bovine brucellosis diagnostic tests. Vet Microbiol. 1996;48:101-12.

12. Jurgensen G, Sorensen V, Giese SB, Stack JA, Riber U. Differentiation between serological responses to Brucella suis and Yersinia enterocolitica serotype 0:9 after natural or experimental infection in pigs. Epidemiol Infect. 2006;134:347-57.

13. Garin-Bastuji B, Hummel N, Gerbier G, Cau C, Pouillot R, Da Costa M, Fontaine $\mathrm{J}-\mathrm{J}$. Non specific serological reactions in the diagnosis of bovine brucellosis: experimental oral infection of cattle with repeated doses of Yersinia enterocolitica O:9. Vet Microbiol. 1999;66:223-33.

14. Ahvonen P. Sievers K. Yersinia enterocolitica infection associated with Brucella agglutinins. Clinical features of 24 patients. Acta Med Scand. 1969; 185:121-5

15. Verstreate DR, Winter AJ. Comparison of sodium dodecyl sulphatepolyacrylamide gel electrophoresis profiles and antigenic relatedness among outer membrane proteins of 49 Brucella abortus strains. Infect Immun. 1984:46:182-7.

16. Santos JM, Verstreate DR, Perera VY, Winter AJ. Outer membrane proteins from rough strains of four Brucella species. Infect Immun. 1984;46:188-94.

17. Cloeckeart A, Vizcaino N, Paquet YJ, Bowden RA, Elzer PH. Major outer member proteins of Brucella spp.: past, present and future. Vet. Microbiol. 2002:90:229-47.

18. Alton $G G$, Jones $L M$, Angus RD, Verger JM. Techniques for the brucellosis laboratory. 1st ed. Paris: Institute National de la Recherche Agronomique; 1988

19. Foster G, Osterman BS, Godfroid J, Jacques I, Cloeckaert A. Brucella ceti nov. Brucella pinnipedialis sp.nov. for Brucella strains with cetaceans and seals as their preferred host. Int. J. Syst. Evol. Microbiol. 2007;57:2688-2693.

20. Moriyon IM, Grillo MJ, Monreal D, Gonzales D, Marin C, Lòpez-Goni I, MainarJaime RC, Moreno E, Blasco JM. Rough vaccines in animal brucellosis: structural and genetic basis and present status. Vet Res. 2004:35:1-38.

21. Adone R, Muscillo M, La Rosa G, Francia M, Tarantino M. Antigenic, immunologic and genetic characterization of rough strains B.abortus RB51, B.melitensis B115 and B.melitensis B18. PLoS One. 2011;6:24073.

22. Corrente M, Desario C, Parisi A, Grandolfo E, Scaltrito D, Vesco G, Colao V, Buonavoglia D. Serological diagnosis of bovine brucellosis using B.melitensis strain B115. J Microbiol Meth. 2015;119:106-9.

23. Jacobson RH. Validation of serological assays for diagnosis of infectious diseases. Rev Sci Tech Off Int Epiz. 1998:17(2):469-86.

24. Italian Regulatory Document. Brucellosi-piani nazionali di controllo. In: Relazione annuale al PNI 2017. http://www.salute.gov.it/relazioneAnnuale2 017/dettaglioRA2017.jsp?cap=capitolo1\&sez=ra17-1-sanimale\&id=1572 Accessed 30 June 2018.

25. Godfroid J, Saegerman C, Wellemans V, Walravens K, Letesson J-J, Tibor A, McMillan A, Spencer S, Sanna M, Bakker D, Pouillot R, Garin-Bastuji B. How to substantiate eradication of bovine brucellosis when aspecific serological reactions occur in the course of brucellosis testing. Vet Microbiol. 2002;90:461-77.

26. Marinaro M, Bellacicco AL, Tarsitano E, Camero M, Colao V, Tempesta M, Buonavoglia C. Detection of Caprine herpesvirus 1-specific antibodies in goat sera using an enzyme-linked immunorbent assay and serum neutralization test. JVet Diagn Invest. 2010;22:245-8.
27. Hinić V, Brodard I, Thomann A, Cvetnić Z, Makaya PV, Frey J, Abril C. Novel identification and differentiation of Brucella melitensis, B. abortus, B. suis, B. ovis, $B$. canis and B. neotomae suitable for both conventional and real-time PCR systems. J Microbiol Methods. 2008;75:375-8.

\section{Publisher's Note}

Springer Nature remains neutral with regard to jurisdictional claims in published maps and institutional affiliations.

\section{Ready to submit your research? Choose BMC and benefit from:}

- fast, convenient online submission

- thorough peer review by experienced researchers in your field

- rapid publication on acceptance

- support for research data, including large and complex data types

- gold Open Access which fosters wider collaboration and increased citations

- maximum visibility for your research: over $100 \mathrm{M}$ website views per year

At $\mathrm{BMC}$, research is always in progress.

Learn more biomedcentral.com/submissions 